\title{
How to Become a Unique Dentist A Quick Manual for Dentists Aiming for Perfection
}

Mohamed Sherine El-Attar

Publisher: ExistlT Publisher

Language: English

ISBN 978-1-62137-066-6

Edition: 3/e

Publish Year: 2013

Pages: 84

Price: $\$ 16.95$

The book "How to Become a Unique Dentist" is a collection of thoughts, experiences and advice which allow the practitioner to achieve perfection.

Professor El-Attar is a professor of prosthodontics at Alexandria University, Egypt and the dean of the Pharos Dental School, Alexandria, Egypt. He divided this guideline in nine chapters: Getting Started, The Office, Professional Ethics, The Maestro, Dental Implants, You and the Others, Controversies, Challenges and Now will you be a unique dentist?

The book shows us the right way to start being a successful dental practitioner which involves collecting as much knowledge as you can and lots of training. He also talks about the dental office organization concept and the way to approach the patient.

The success of your office depends on your decision of the best treatment plan (with the patient's consent of course). If you respect the occlusion, if you use splinting in periodontally involved teeth and if you choose permanent prosthetic temporization, you

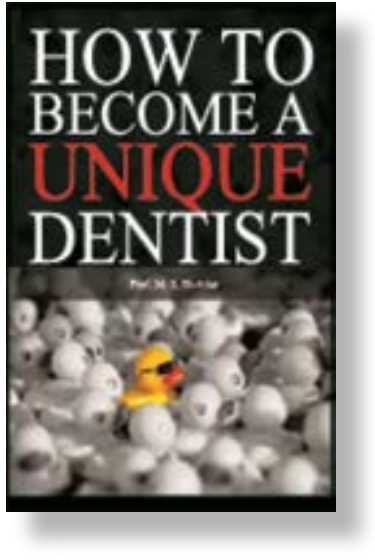

have all the chances to "be a good prosthodontist, be the maestro".

Professor El-Attar also considers that a natural tooth is a "treasure" to be preserved by endodontic treatment. In case the natural root cannot be saved due to the endodontic problematic tooth he recommends dental implants as every unique dentist has to deal with implants.

Dental specialties are interdependent; choosing one specialty is recommended but you have to practice it with greater professional skill.

Only the young practitioner who carefully reads and follows exactly the advice outlined in the current guide can become a successful practitioner fulfilling his dream of being "A Unique Dentist". 